\author{
Military Technical College \\ Kobry El-Kobbah, \\ Cairo, Egypt.
}

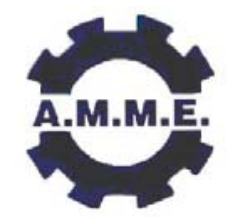

\title{
INVESTIGATION OF LOW END TORQUE DIP PROBLEM OF CAMPRO 1.6L ENGINE
}

\author{
MOHIUDDIN* A.K.M., RAHMAN ${ }^{* *}$ A., ARFAH ${ }^{+}$A. and FARRAEN ${ }^{++}$M.A.
}

\begin{abstract}
The main objective of this work is to perform an extensive study on the causes of the torque dip in CAMPRO engine and subsequently to provide the best solution that will improve the performance, reliability as well as production cost. CAMPRO engine is a basic Double Overhead Camshaft (DOHC) which has a capacity of $1597 \mathrm{cc}$ and installed with a total of 16 valves developed by Malaysian car manufacturer PROTON in the year 2000.The CAMPRO engine experiences performance downfall when it reaches at certain rpm. The phenomenon is known as torque dip or torque loss where the output torque is not smooth, consequently formed a dip in the torque curve. The dip which occurs at $2500-3500 \mathrm{rpm}$ is mainly influenced by the geometry of the designed intake manifold and valve timing. Analysis is mostly confined on the intake manifold geometry and the valve timing. Two possible solutions viz., dual length intake manifold and variable valve timing are analyzed.
\end{abstract}

\section{KEY WORDS}

CAMPRO Engine, Torque Dip, Manifold Geometry, Valve Timing, GT-Suite.

* Professor, Dpt. of Mech. Engineering, International Islamic University Malaysia.

** Asst. Prof., Dpt. of Mech. Engineering, International Islamic University Malaysia.

+ Grad. student, Dpt. of Mech. Engineering, International Islamic University Malaysia.

++ Grad. student, Dpt. of Mech. Engineering, International Islamic University Malaysia. 


\section{INTRODUCTION}

An automotive engine known as CAMPRO has been developed by Malaysian car manufacturer PROTON in the year 2000. The CAMPRO engine is a basic Double Overhead Camshaft (DOHC) which has a capacity of $1597 \mathrm{cc}$ and installed with a total of 16 valves. The bore and stroke dimensions of each cylinder is $76 \mathrm{~mm}$ and $88 \mathrm{~mm}$ respectively. It is claimed to produce 110 bhp $(82 \mathrm{~kW}) @ 6500$ RPM and $148 \mathrm{Nm}$ of torque [1]. Despite of the great achievement, PROTON is facing a problem with the performance of its engine. In order to compromise the maximum torque and achieving the required emission level, PROTON engineers had to sacrifice the performance of the low-end torque of the engine. Therefore, unlike any other average performance engines, the CAMPRO engine experiences performance downfall when it reaches at certain rpm. The phenomenon is known as torque dip or torque loss where the output torque is not smooth, consequently formed a dip in the torque curve. The dip which occurs at $2500-3500 \mathrm{rpm}$ is mainly influenced by the geometry of the designed intake manifold and valve timing. The main objective of this work is to perform an extensive study on the causes of the dip in CAMPRO engine and subsequently to provide the best solution that will improve the performance, reliability as well as production cost. The analysis is mostly confined on the intake manifold geometry and the valve timing. This is done by simulating similar model of CAMPRO in the GT SUITE software and acquired the results of changed intake geometry and valve timing on the output torque.

GT-SUITE is an integrated set of computer-aided engineering (CAE) tools developed by Gamma Technologies, Inc. to address engine and power train design [2]. These tools are contained in a single executable form which is essential to its use in "Integrated Simulations". GT-SUITE comprised of six solvers (GT-Power, GT-Drive, GT-Vtrain, GT-Cool, GT-Fuel, and GT-Crank), a model-building interface (GT-ISE), a powerful post-processing package (GT-POST), and a collection of supporting tools [3]. GT-ISE provides the user with the graphical user interface (GUI) that is used to build models as well as the means to run all GT-SUITE applications. GT-SUITE comes with an individual solver specifically to assist engineers in the design of valve trains which is called GT-VTRAIN. A useful tool included in GT-VTRAIN is the VT-Design. Valve train Design (VT-Design) is a stand-alone, interactive polynomial cam design/valve train mechanism design tool supplied with GT-SUITE that may be used as a preprocessor to the following applications: GT-POWER, GT-VTRAIN and GT-FUEL. Two distinct features of the tool are Cam Design and Valve Train Kinematics.

From the analysis it can be concluded that the torque dip phenomenon is caused by the pressure wave that is not coherent with the valve opening. The traveling pressure wave which is supposed to arrive at the time the intake valves are opening will be induced into the cylinder as a result of the vacuum effect created by piston's downward motion. The shape of the torque curve is largely dependent on the runner geometry, valve timing and pressure wave arrival.

\section{GT POWER: CAMPRO ENGINE MODEL}

A GT-Model is created to model the CAMPRO engine. The model data were referred from PROTON Power train department database [1]. Due to insufficient information, some data were taken from default value [2]. Fig. 1 shows the model of the CAMPRO in 
GT Power. Variation of torque with rpm for the CAMPRO 1.6L engine and its GT Power model is shown in Fig.2.

\section{ANALYSIS}

\section{Intake Manifold Phenomenon}

Intake manifold is a complex part of the engine. The pressure behavior is relatively complex due to the negative and positive pressure wave oscillation in the manifold. The intake system can be modeled as a spring-mass system. A series of pulsating waves of expansion and compression are occurring in the intake runner. The wave travels back and forth in the runner due to inertia. The pressure at the port builds up when the valve is closed (Fig.3). As it builds up, the pressure wave travels back and forth creating an oscillating wave. Theoretically, when the timing of the pressure wave is right, the pressure wave will travel towards the cylinder when the valve is open and the pressure at the port falls below atmospheric pressure. At the maximum opening of the valve, the positive pressure starts to drop as the valve starts to close. The pressure in the port will start to increase as the valve closes. When the valve is fully closed, the pressure wave travels backward as a negative pressure wave. Then, the pressure wave travels back to the valve again until the valve is open for the next cycle. According to Lumley [4], as seen in the pressure graph in Fig. 4, the pressure in the intake manifold can be modeled as a loaded spring and is released. The fluid in the runner oscillates in similar manner as the spring-mass system. The oscillations dampen until the valves open again.

Referring at crank angle where the valve is at its maximum opening in Fig.5, the pressure for the operating range other than $3000 \mathrm{rpm}$ is much lower. Low pressure at the port when the valve is opening indicates pressure flowing into the cylinder. Therefore the pressure at $3000 \mathrm{rpm}$ during valve opening is higher in magnitude than the pressure at $2500 \mathrm{rpm}$ during valve opening. It shows that the pressure wave that sucked into the cylinder is lower at $3000 \mathrm{rpm}$ than at $2500 \mathrm{rpm}$, consequently producing less torque and power. This is where the torque dip occurs. This happens mainly because of the timing the pressure arrives at the valve. If the pressure wave arrives later than it supposes to be, then the pressure at $3000 \mathrm{rpm}$ can be lowered and more pressure may enter the cylinder. To make the pressure at $3000 \mathrm{rpm}$ arrives later; the length of the runner has to be changed so that the pressure of $3000 \mathrm{rpm}$ at maximum opening of valve is lower than the pressure of $2500 \mathrm{rpm}$ at maximum opening. Then, it will have higher cylinder pressure at maximum valve opening. It is important to tune the length [5] accordingly, so that maximum cylinder pressure at the maximum valve opening can be achieved.

The runner length of the CAMPRO engine is optimized for higher torque at high rpm. So, the length is much shorter than other manufacturer's intake runner design. The low end torque is sacrificed and the torque dip occurs between 2500 and 3500 rpm (Fig. 6). The torque dip occurs only at this particular range because the valve timing and the pressure wave arrival time is not coherent at this range. The pressure wave arrives too early before the valve opens. The pressure arrival time at 3000 RPM is earlier than the opening of the valve. So, less pressure enters the cylinder. The oscillation at low rpm is more than the oscillation of higher rpm. At low engine speed, the valve opens and 
closes at a lower speed. So, the pressure wave formed in the intake runner bounces back and forth much more until the valve reopens. This explains why the oscillation at lower rpm is more than that at higher rpm. The more oscillations, the unstable the pressure forms at the intake port. The number of effective pressure wave assisting the fluid flow is higher. So, the study of the pressure wave effects is only limited to rpm higher than 2500.

Referring to Fig. 7, the torque dip at rpm less than 2500 is not significant because the number of oscillations is more than that at other rpm. As the rpm increases the number of pressure wave oscillations is reduced per stroke. And the pressure wave arrives earlier. It is to be noted that the oscillations for different rpm is running at different phases. Coincidently, the pressure wave at higher rpm arrives later than at lower rpm. The pressure wave is much affected by the intake manifold design itself. The waves from other cylinders runner can cause interferences that reduce or increase the pressure wave.

\section{Affecting Parameters}

It is evident from the performance curve of the CAMPRO 1.6L engine that at the point where the dip occurs; a downfall of the volumetric efficiency also occurs at that point (Fig. 8). The volumetric efficiency is influenced by many factors such as the density of the fresh charge, the amount of exhaust gas in the clearance volume, the design of the intake and exhaust manifold and also the valve timing [6]. The volumetric efficiency is the breathing capacity of the engine during the opening and closing of the intake and exhaust valves. Therefore the volumetric efficiency is inter-related with the pressure wave [7]. In order to enhance the volumetric efficiency and to eliminate the torque dip, two parameters are considered, viz., runner length and diameter, and also the valve timing.

\section{Intake runner length}

For optimum performance result, an appropriate length and diameter of the manifold should be used to get as much as possible of air/fuel mixture into the cylinder in time. The main key of the design of intake manifold is to provide maximum possible fresh charge during the intake stroke. In addition, by moving the air as fast as possible into the cylinder, we can increase the turbulence. Thus the mixing operation will be accelerated. The runner length controls the timing of the returning waves. With correct length of intake runner, it helps the wave in the runner to return at the port at correct time. But with the valve closing, the air cannot go anywhere and it piles up and became compressed. The compressed air must be diverted so that it turns around it and will flow back through the intake runner in the form of pressure wave (manifold pressure) at the time when the valve is opened and bounces back and forth. If timed properly, it will arrive at the port when the valve is opened again and the extra pressure can force extra air drawn into the engine thus increasing the volumetric efficiency. The amplitude of the pressure wave i.e., nearest to the maximum valve opening is the main concern. The pressure wave arrival time can be controlled by increasing or decreasing the length. By increasing the length, we can increase the travel duration, thus later arrival and vice versa. A simulation using GT Power is conducted to validate this behavior of the fluid in the intake manifold. A series of test were conducted with two different runner lengths of $400 \mathrm{~mm}$ and $633 \mathrm{~mm}$. The intake port pressure plotted for $6000 \mathrm{rpm}$ is shown in Fig. 9 . 


\section{Valve timing}

Valve timing is the regulation of the points in the cycle at which the valves are set to open and close. The CAMPRO valve timing is used as reference to understand the standard values used by car manufacturers. The exhaust valve is open $45^{\circ}$ before the exhaust stroke. The exhaust valve is open early so that the cylinder pressure will help the exhaust gas move out of the cylinder quickly. Then, the intake valve opens $12^{\circ}$ before TDC. Both the intake and exhaust valves are open during the period known as "Valve Overlap". Valve overlap helps to pull the air into the cylinder by the suction effect created by the exiting exhaust gases. This helps to increase the volumetric efficiency of the engine. The intake valve is kept open until $48^{\circ}$ after BDC. Due to inertia the air continues to flow even when the piston is moving upwards during the compression stroke. When the valve is opened, it creates vacuum and the pressure wave is theoretically minimum before the valves reach its maximum opening. Fig. 10 shows the pressure wave for 2000, 2500 and $3500 \mathrm{rpm}$ which is not coherent with the maximum opening as in the other engine speeds. This is the cause of the torque dip. Changing the valve timing changes the opening and closing angle of the valves and thus changes the overlap angle. During the valve overlap, the intake and exhaust valves are open simultaneously creating a path for the fresh charges to flow into the exhaust. But a well designed engine can minimize the flow. The main objective of this work is to eliminate the torque dip at the $2500-3500 \mathrm{rpm}$ range. According to Lumley [4], improvement of the low-speed torque of an engine can be achieved by advancing the intake valve opening.

\section{ANALYSIS OF POSSIBLE SOLUTIONS}

\section{Dual Length Intake Manifold}

The shape of the torque curve is largely dependent on the runner geometry and pressure wave arrival. By using a longer runner, the average torque at low rpm is increased. The torque loss at low rpm is also decreasing, at some extent the torque dip disappears. This is mainly due to sufficient amount of air provided to the engine during low rpm operation with less air velocity. The engine breathes well at low rpm. However, the torque at high rpm is sacrificed because of insufficient amount of air provided to the engine. The engine is "chocked" when a long runner is used. For the short runner it is completely opposite to the long runner effect. It performs well at high rpm. Therefore, to get the advantages of both options, some car manufacturers adapted the Variable Intake Manifold or Dual Length Intake Manifold. This type of manifold provides the best performance of using long and short runner. At first, the engine is tested with long runner and optimized the length to provide the best torque at low rpm. Then the engine is fitted with a short runner and is again optimized for a higher rpm torque. Then, both the runners are integrated as one unit with a flapping system to control the flow of air into both channels. The intake runner flap mechanism as shown in Fig. 11 is controlled via a control system designed specifically for variable intake manifold. The flap controls the opening channel of the runner. The flap opening angle is opened based on the optimized opening rpm. The default runner i.e., long runner is opened at rpm below 3500 . Above $3500 \mathrm{rpm}$, the flaps turn and open the short runner channel. Air flows through the short runner providing higher air intake velocity. To design the Dual Length Intake Manifold, the engine is simulated in GT POWER with initial runners and then 
shorter runners are tested. After numerous engine simulations, it is concurred that the length of the primary pipe is varied because it provides the biggest gain in torque. The secondary pipe is retained. This design also helps to make the intake manifold design simpler. After several testing, the long and short runners are optimized to $740 \mathrm{~mm}$ and $540 \mathrm{~mm}$ respectively. The diameters are altered to get smoother torque at low end rpm. The long runner diameters are changed from $46 \mathrm{~mm}$ and $35 \mathrm{~mm}$ to $40 \mathrm{~mm}$ and $30 \mathrm{~mm}$ respectively to ensure enough pressure supply to the intake runners at 1000 to 2000 rpm. The flap diameter is increased from $46 \mathrm{~mm}$ to $48 \mathrm{~mm}$ to obtain larger effective flow area of the flap. The DLIM model built in GT POWER is shown in Fig. 12. The performance comparison between base CAMPRO model and Dual Length Intake Manifold Model is shown in Fig. 13. The overall mid range torque is increased. The torque dip disappears due to increased in torque. However, high rpm torque is lowered. Torque starts to fall somewhere after $4500 \mathrm{rpm}$. The main objective which is to lessen the torque dip has been achieved.

\section{Variable Valve Timing}

From extensive analysis on the torque dip, it is understood that the pressure wave arrival time is dependent on the runner length and timing of the valve opening. By adopting variable valve timing, the engine performance can be raised and have better idling stability. The intake valve closing, valve overlap and cam timing angle can be varied throughout the engine operating speeds to produce a smoother torque while maintaining higher performance. In the GT POWER software, the CAMPRO Variable Valve Timing (VVT) model is built as the base model with added controlling mechanism to precisely control the cam timing angle. The main focus is on the low end engine speed. However, at $4500 \mathrm{rpm}$, the cam is slightly advanced to produce a smoother torque. In the GT model, actuator was placed directly to the valve. The controlling parameter was the cam timing angle. Similar control system was adapted from the Dual Length Intake Manifold model. The Variable Valve Timing of CAMPRO GT model is shown in Fig. 14.

Fig. 15 shows the torque curve produced by the variable valve timing is much smoother than the base performance. With variable valve timing, it is possible to control the pressure wave at each rpm. Thus, more optimized torque is produced. Fig. 15 is the performance result of the CAMPRO GT model equipped with the Variable Valve Timing system. The hike in torque at $2500 \mathrm{rpm}$ is reduced to a more desirable value. The timing at $2500 \mathrm{rpm}$ was retarded by $3^{\circ}$. The torque at the torque dip range is increased. At $4500 \mathrm{rpm}$, the performance is much smoother since the timing was advanced by $2^{\circ}$.

\section{CONCLUSION}

The main objective of this work has been performed successfully. The causes of occurrence of torque dip between the ranges of $2500 \mathrm{rpm}-3500 \mathrm{rpm}$ are thoroughly investigated. It can be concluded that the torque dip phenomenon is caused by the pressure wave that is not coherent with the valve opening. The traveling pressure wave which is supposed to arrive at the time the intake valves are opening will be induced into the cylinder as a result of the vacuum effect created by piston's downward motion. The shape of the torque curve is largely dependent on the runner geometry, valve 
timing and pressure wave arrival. The long and short runners of Dual length intake manifold are optimized. Reduction in torque dip is also achieved.

\section{REFERENCES}

[1] http://www.proton.com/innovation/rnd/campro.php, (2005)

[2] Gamma Technologies, GT-Suite, http://www.gtisoft.com, (2004).

[3] GT-suite V6.1 User's Manual, Gamma Technologies, (2004).

[4] Lumley, John, L., , Cambridge University Press, (2000).

[5] Hartman, J., How to Tune \& Modify Engine Management Systems, MBI Publishing Company, (2003).

[6] Ganesan, V., Internal Combustion Engines Second Edition. Mc Graw-Hill., (2004).

[7] Ohata, A., and Ishida, Y., "Dynamic Inlet Pressure and Volumetric Efficiency of Four Cycle Four Cylinder Engine" SAE paper 820407, SAE Trans., vol. 91, (1982). 


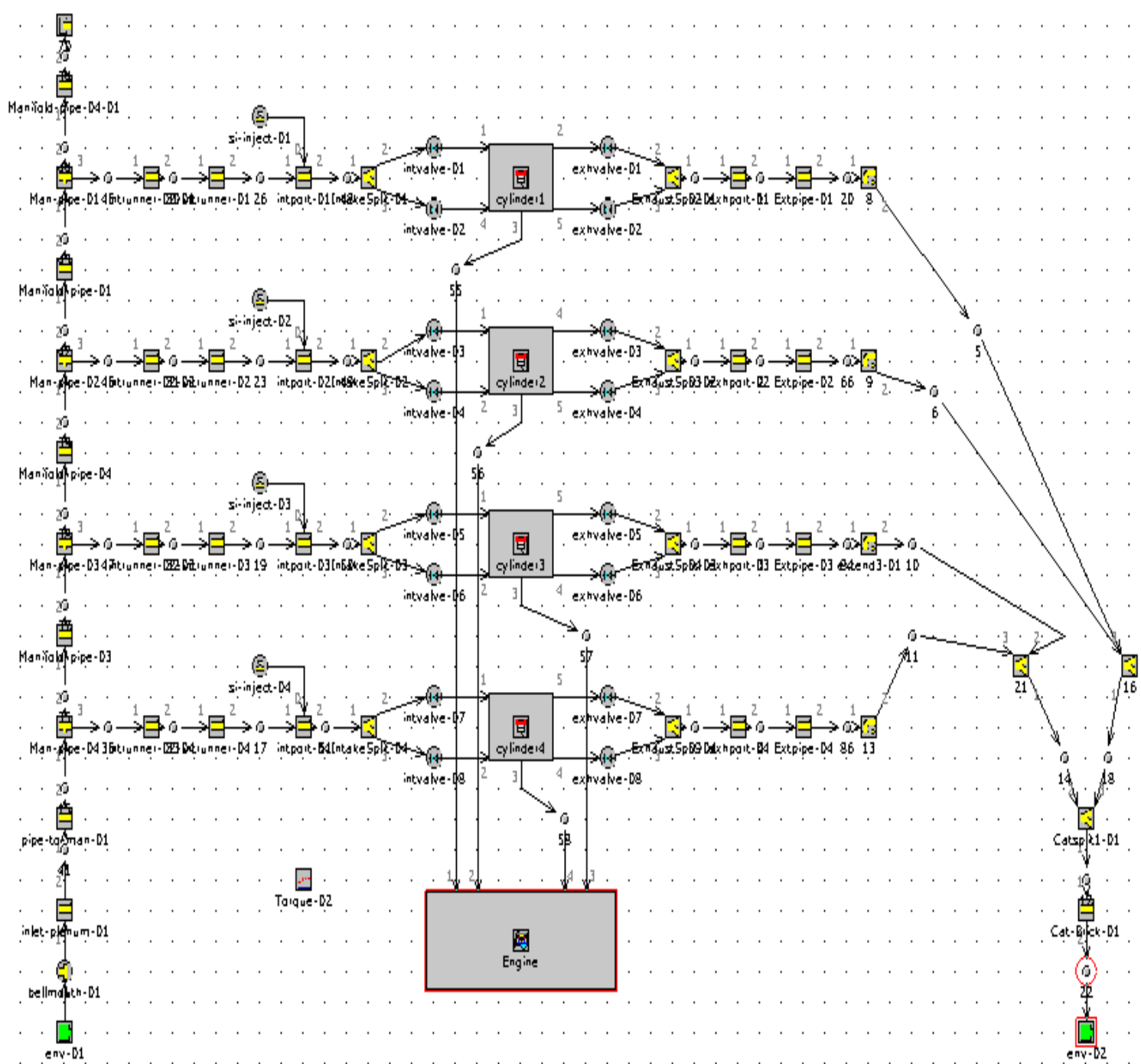

Fig.1. CAMPRO model in GT Power

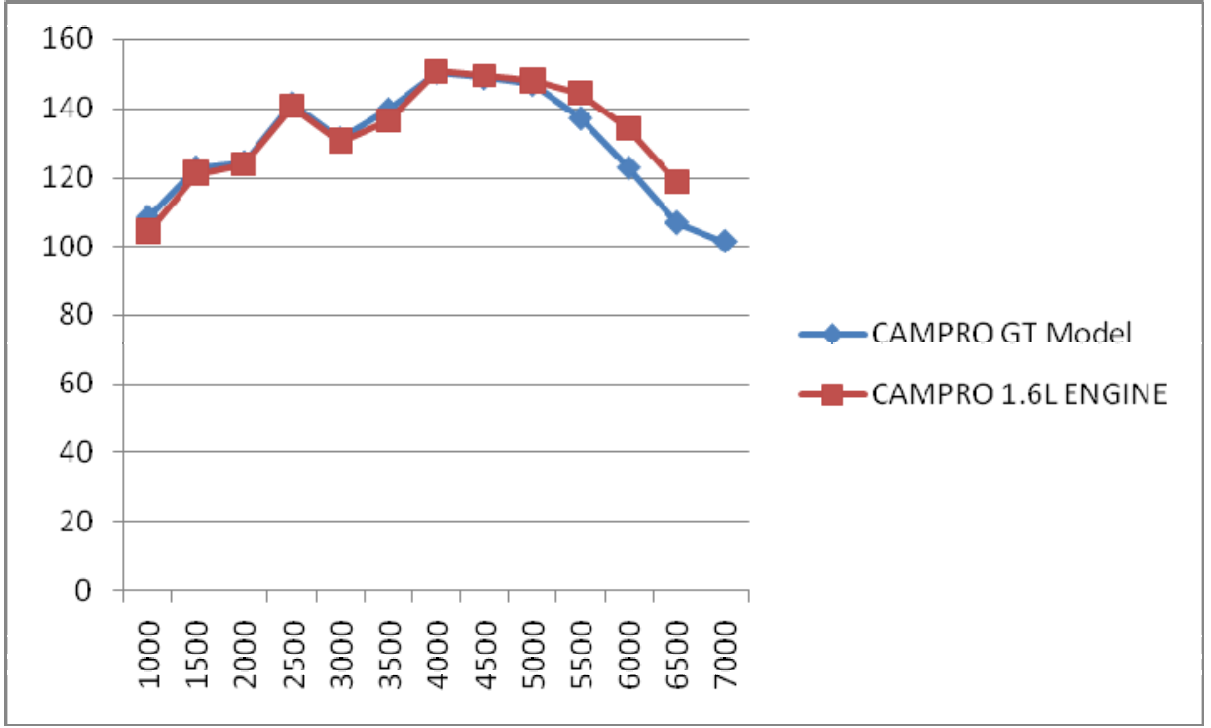

Fig.2. Variation of torque with rpm for the CAMPRO 1.6L engine and its GT model 


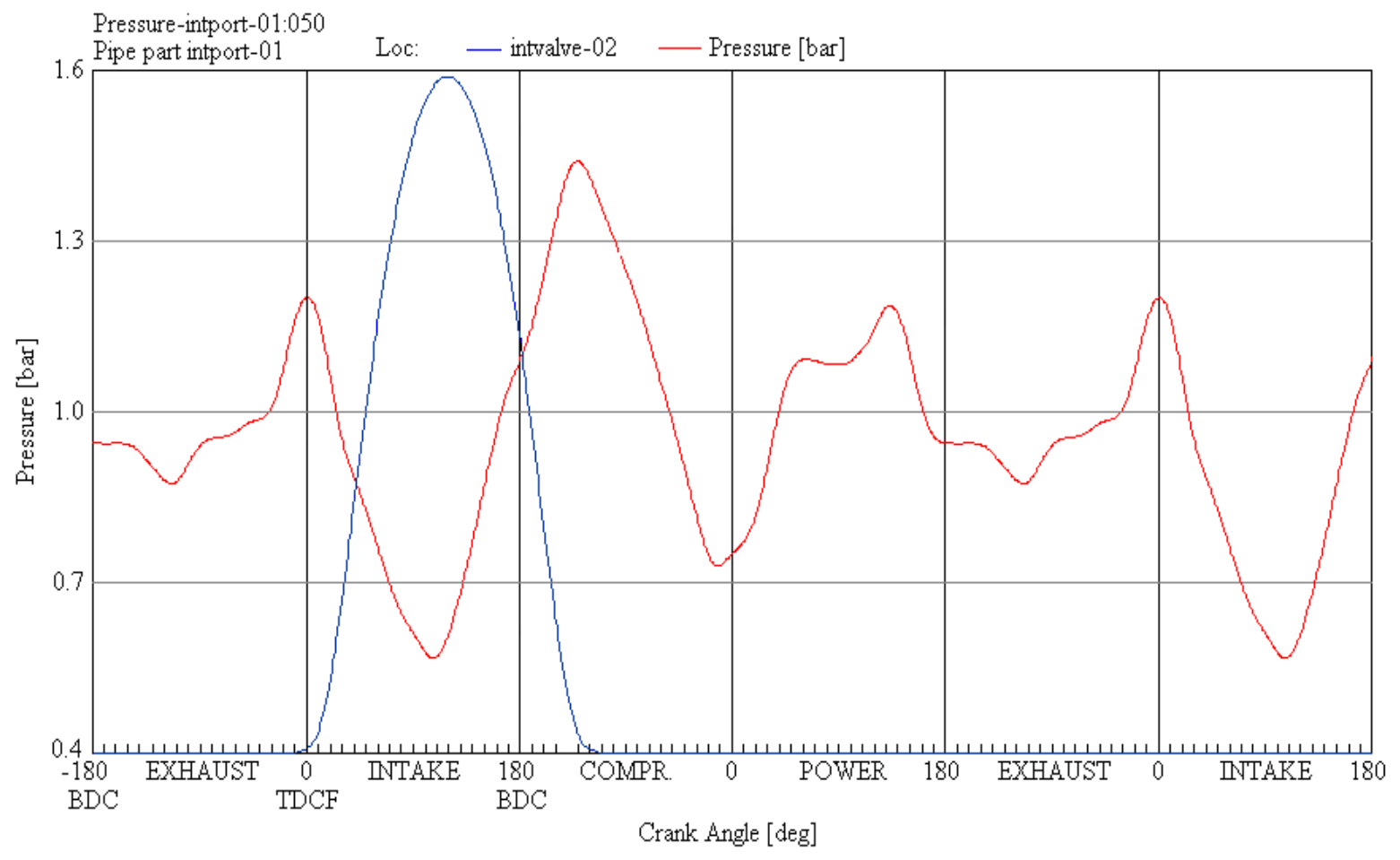

Fig.3. Intake port pressure vs. crank angle at $6000 \mathrm{rpm}$

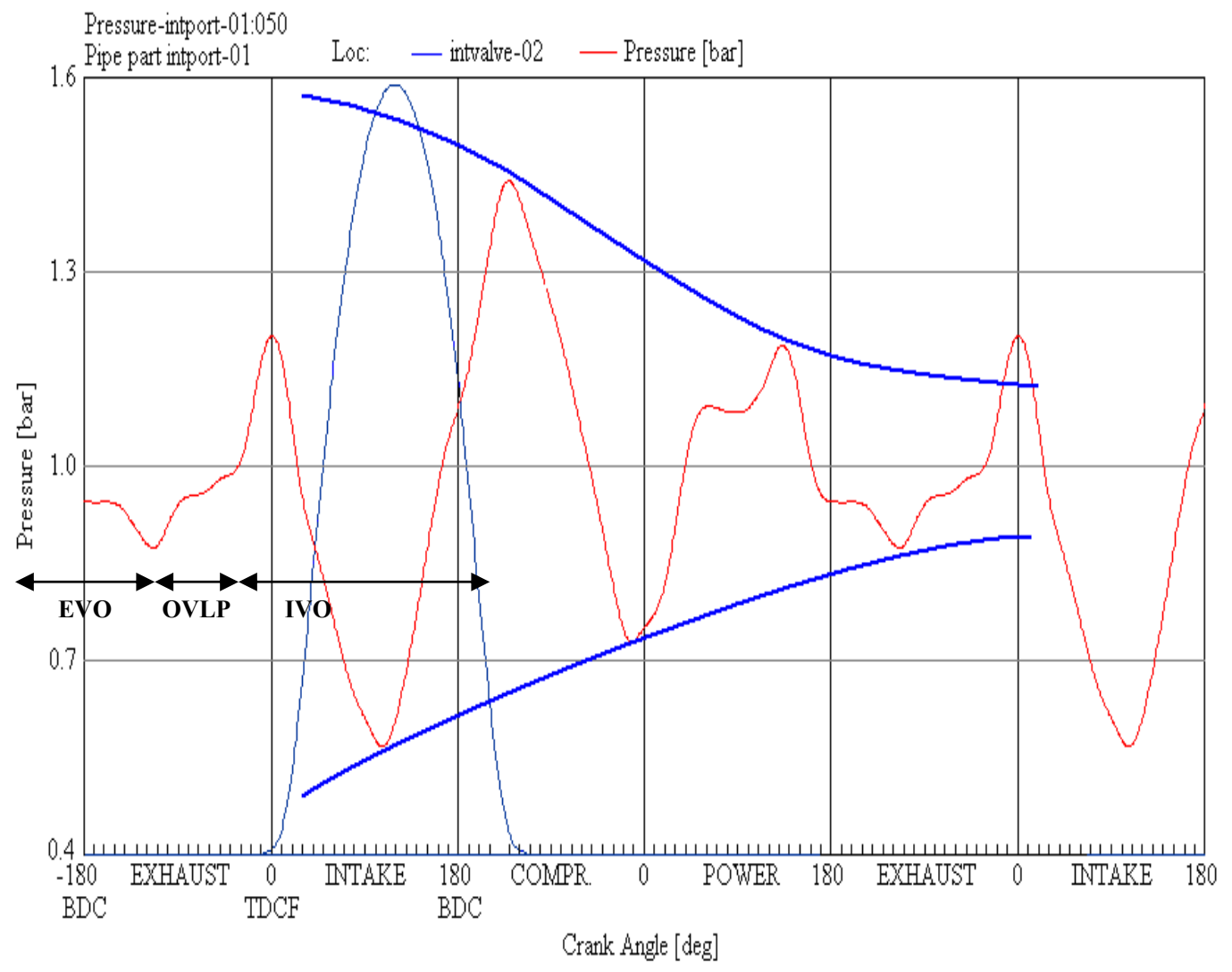

Fig.4. Valve timing and pressure oscillation in intake manifold 


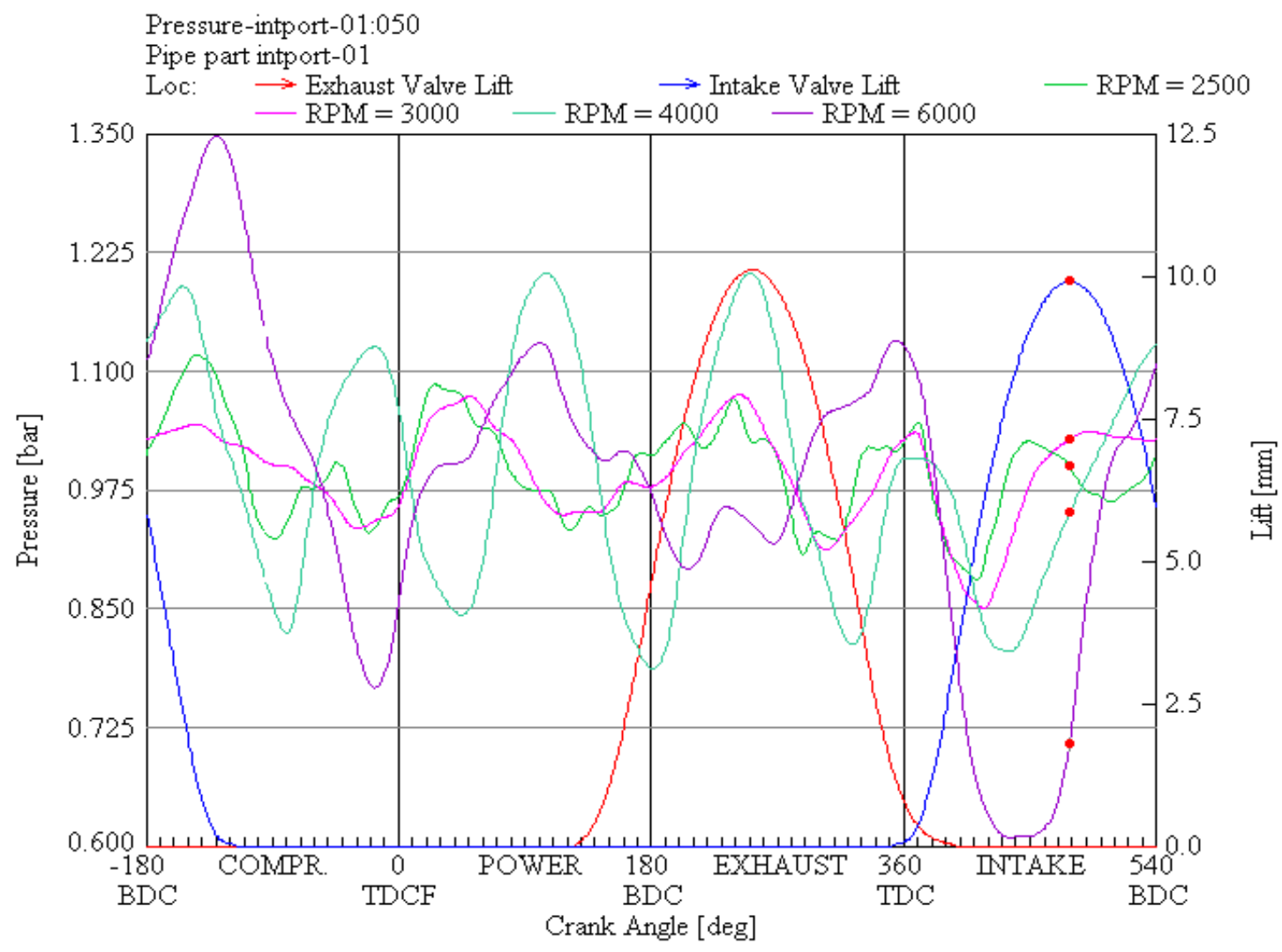

Fig.5. Intake port pressure and intake valve lift vs. crank angle

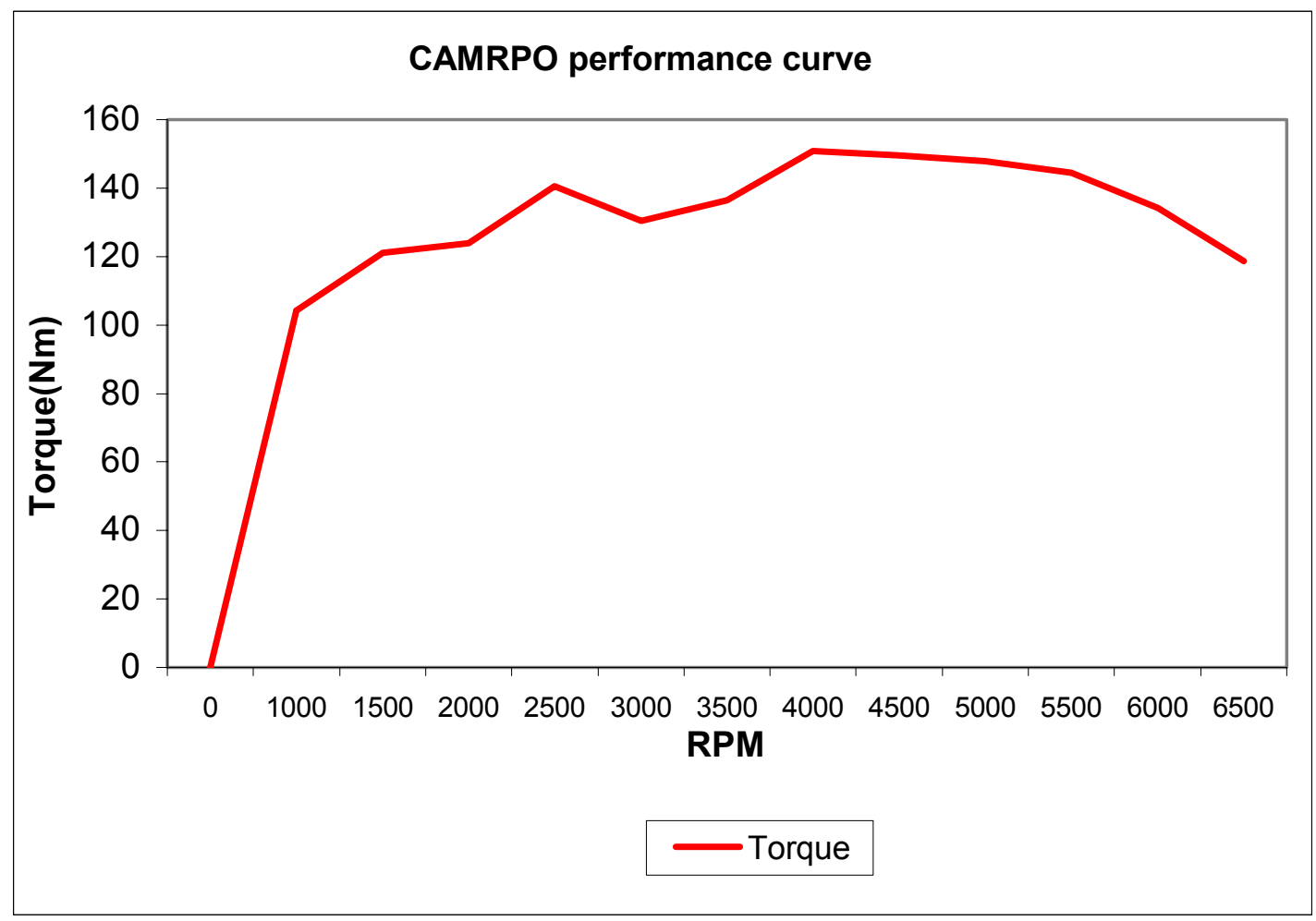

Fig. 6. CAMPRO torque curve 


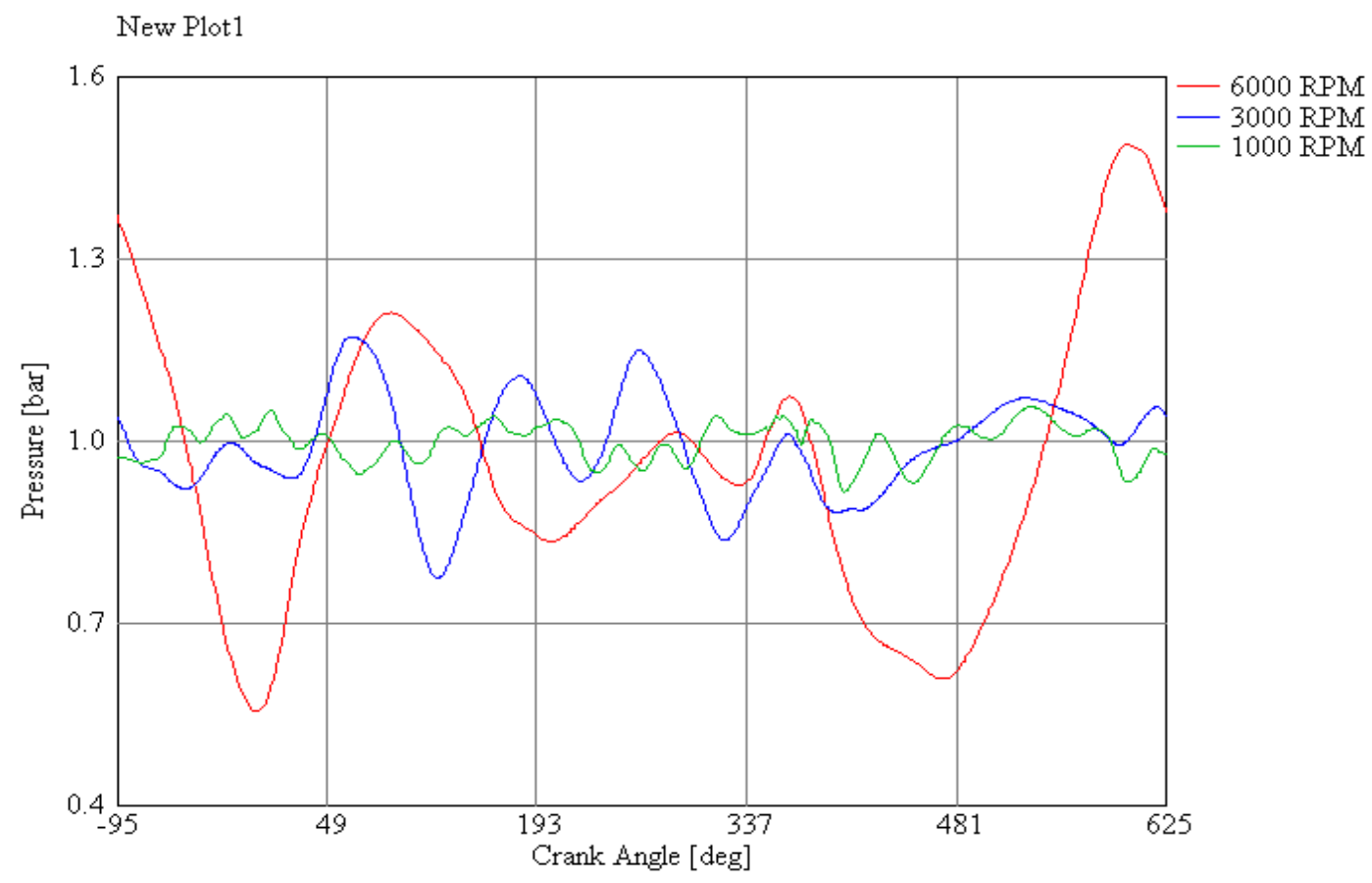

Fig. 7. Intake port pressure vs. crank angle

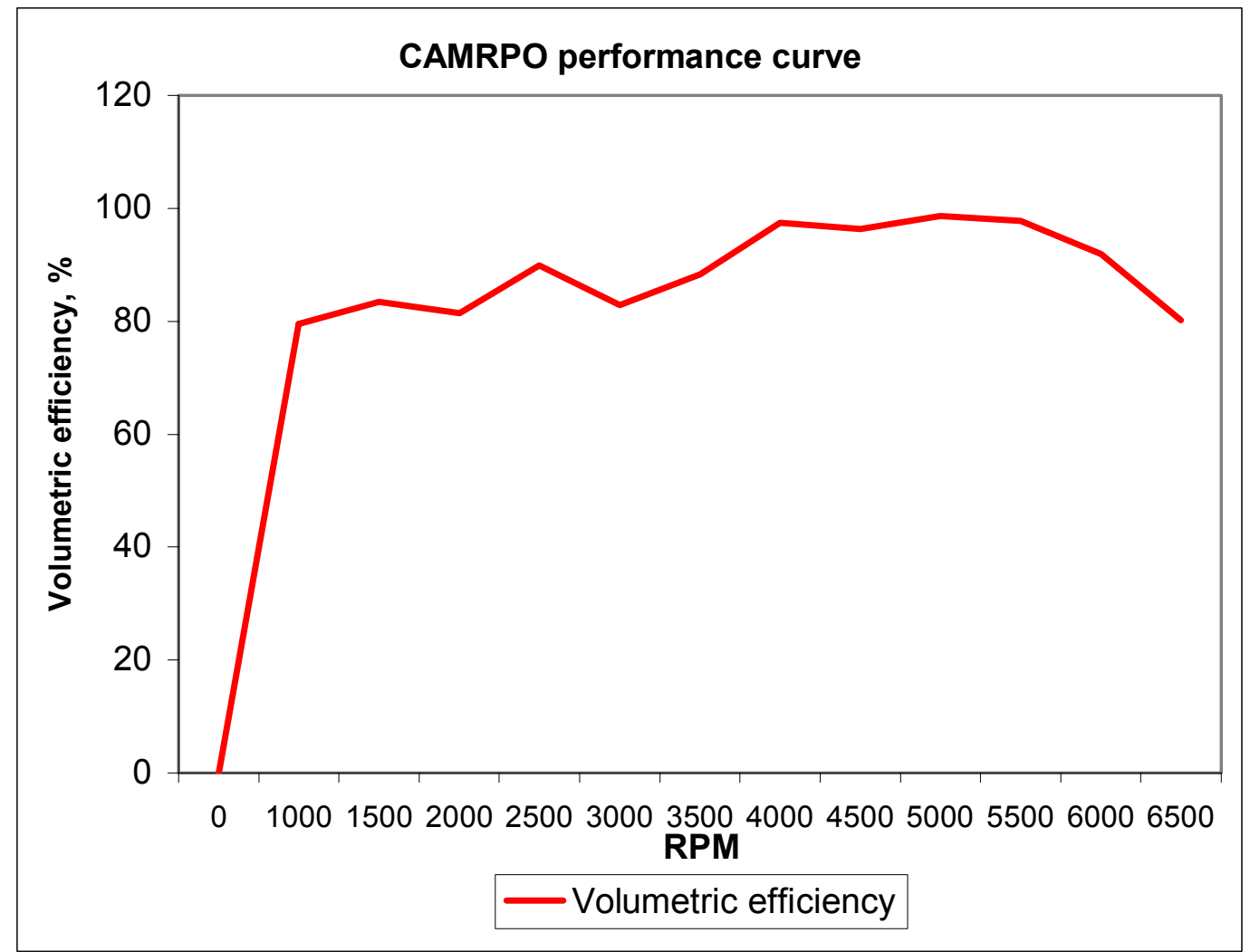

Fig. 8. CAMPRO volumetric efficiency curve 


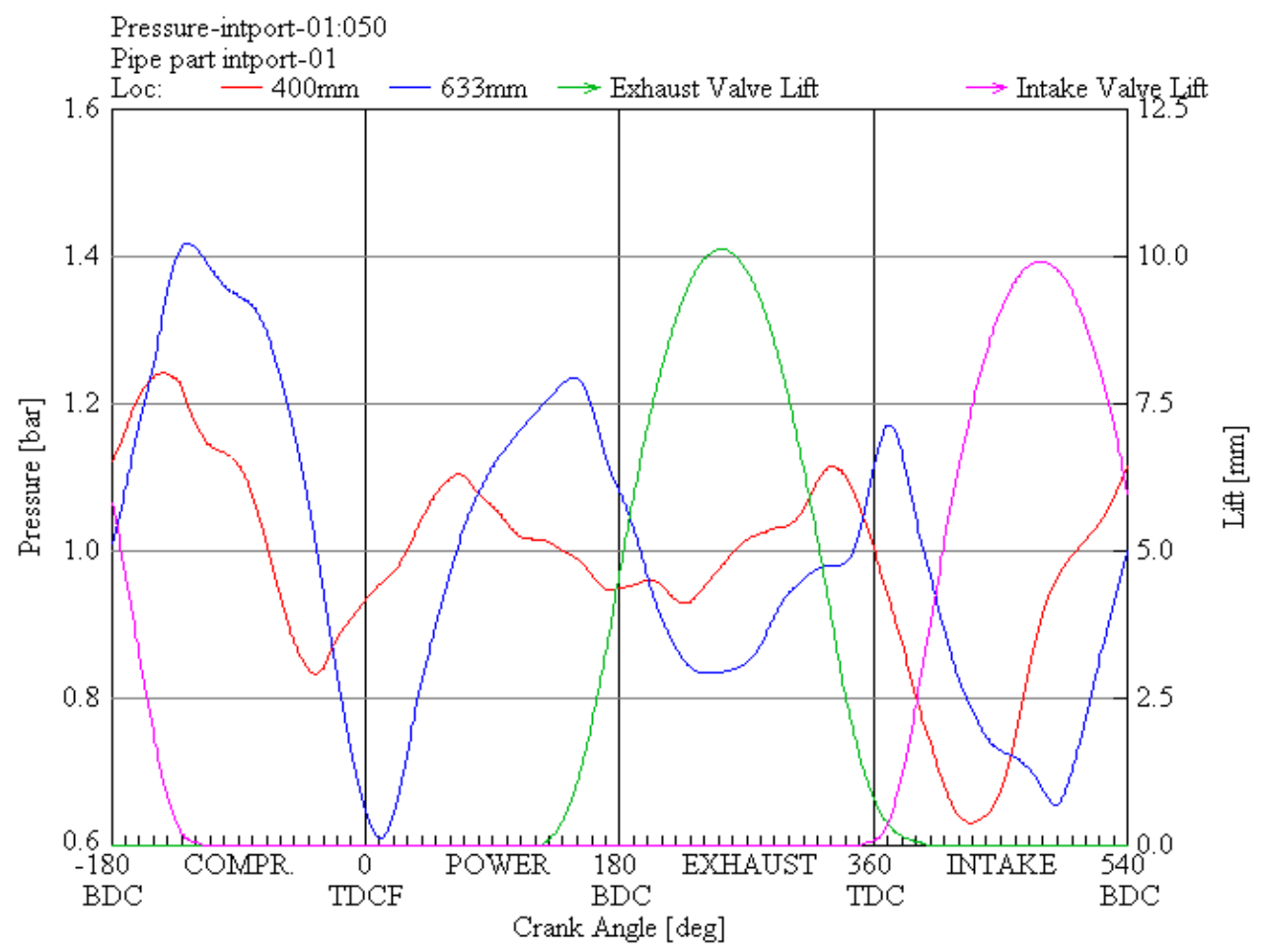

Fig. 9. Intake Port Pressure for $400 \mathrm{~mm}$ and $633 \mathrm{~mm}$ at $6000 \mathrm{rpm}$

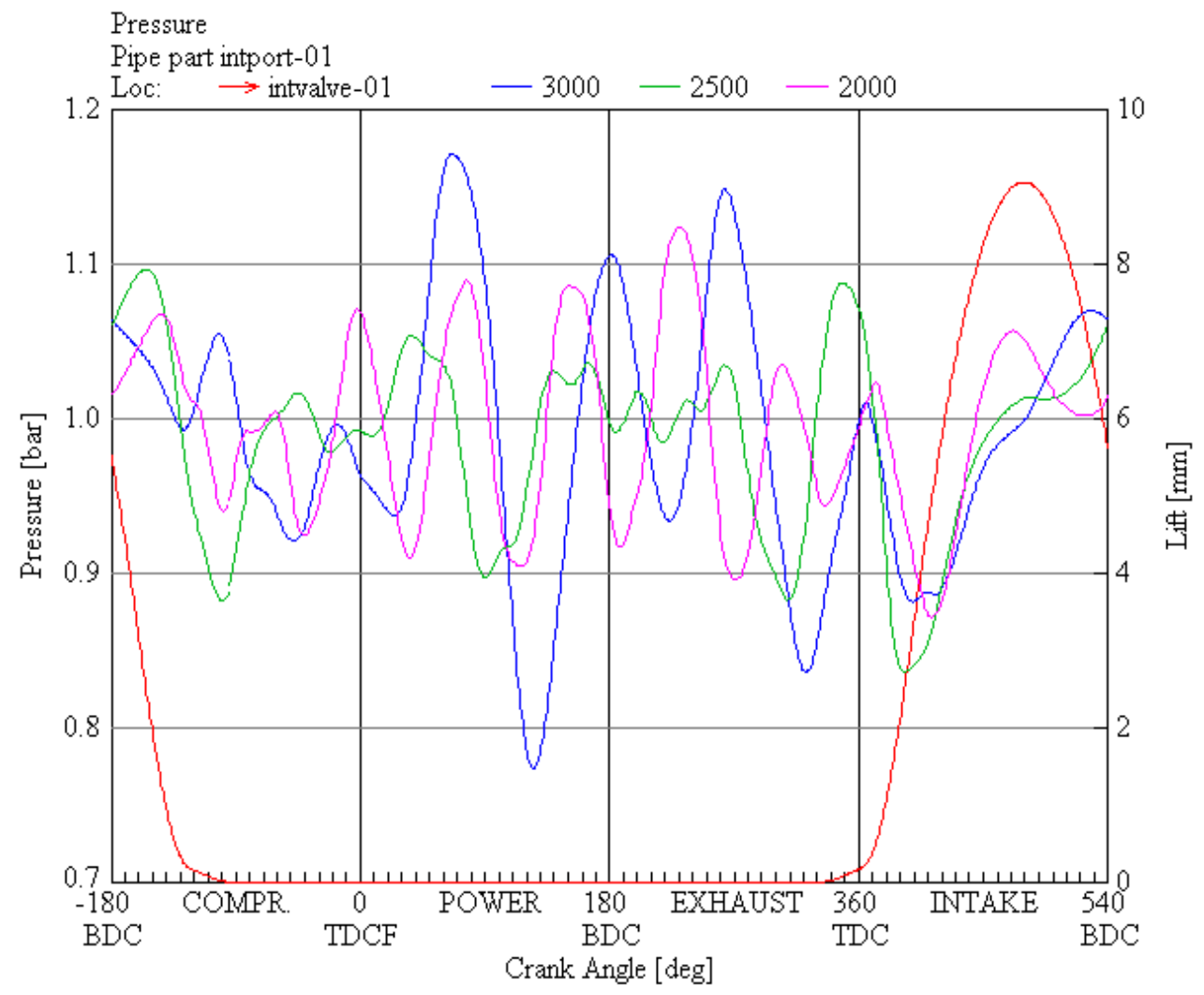

Fig. 10. Intake Port Pressure at 2000, 2500 and 3000 rpm 


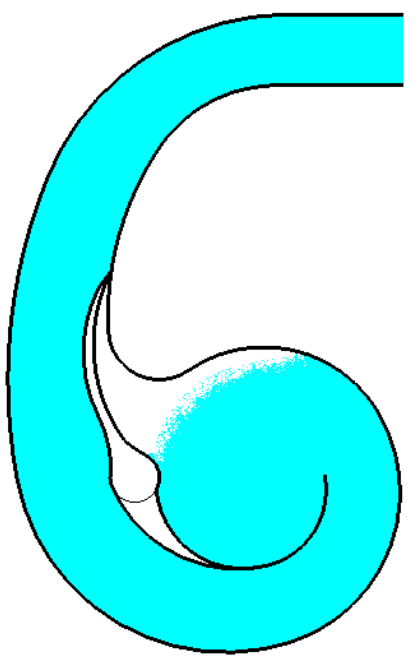

Long runner

Operation

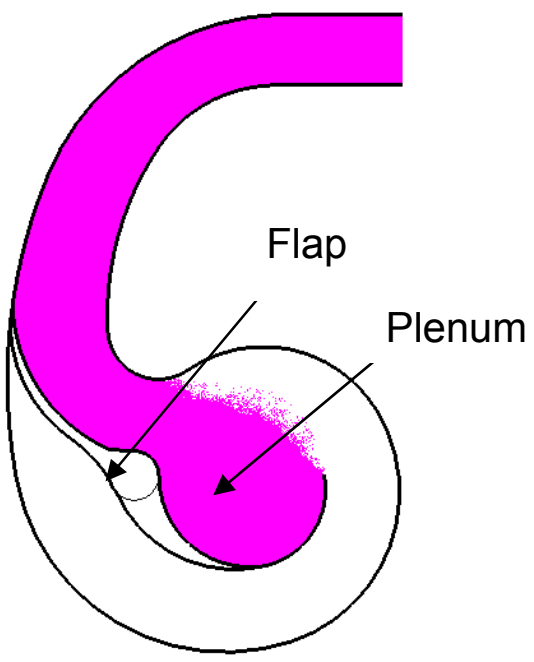

Short runner operation

Fig. 11. Short and Long Runner Operation

Intake Plenum

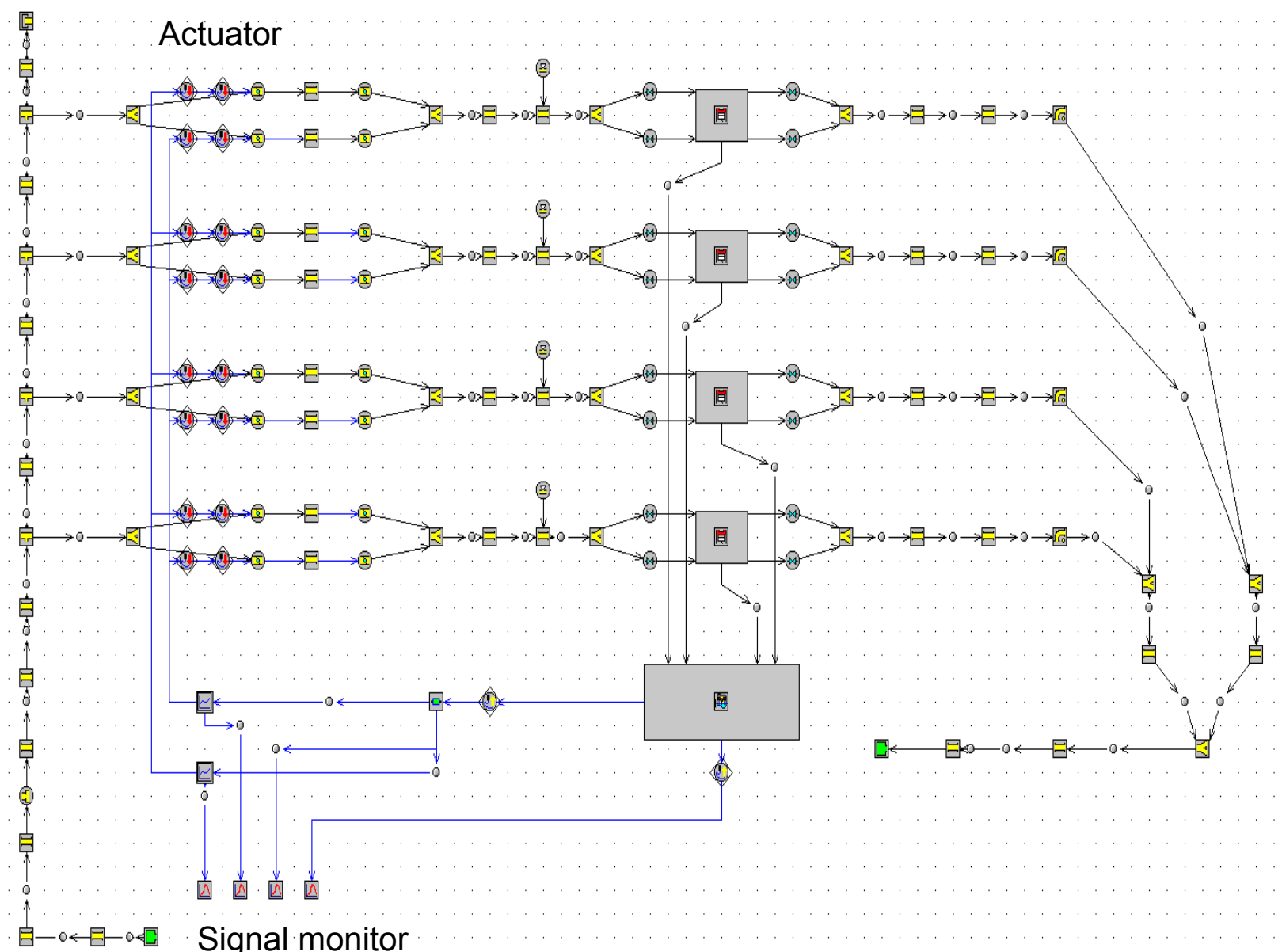

Fig. 12. GT-Model of dual length intake manifold 


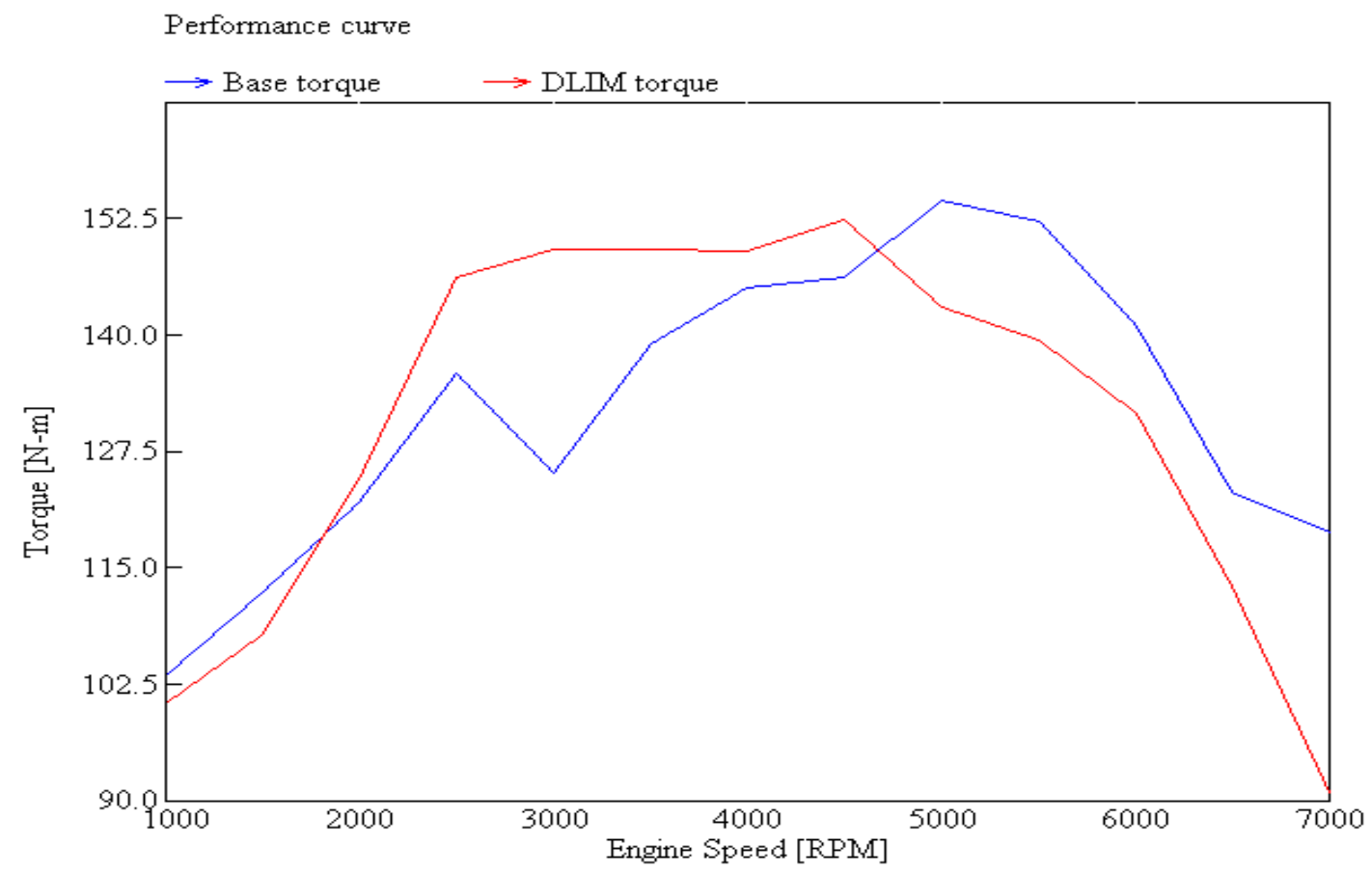

Fig. 13 Performance test result for dual length intake manifold - Torque

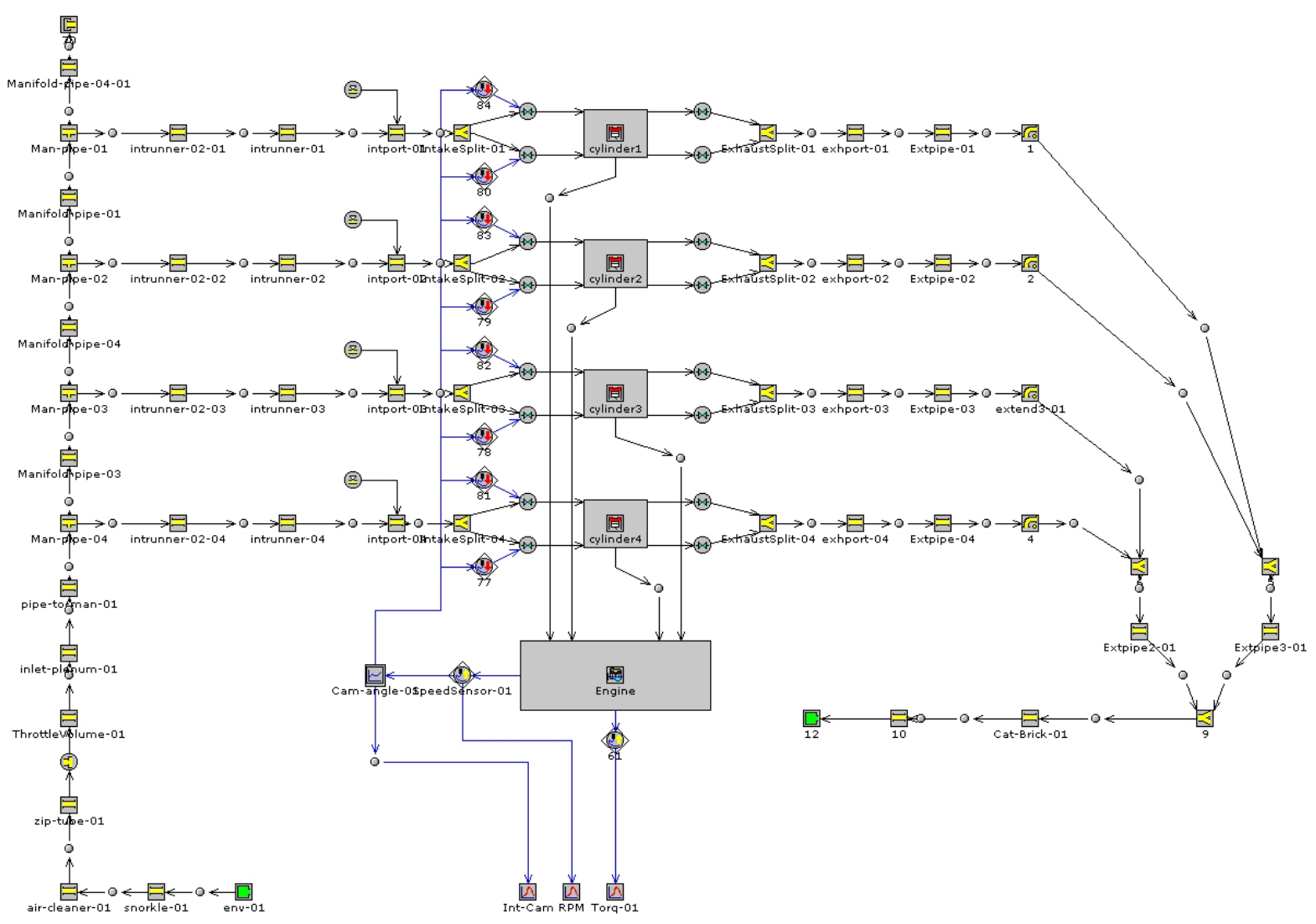

Fig. 14. Variable valve timing of CAMPRO GT model 


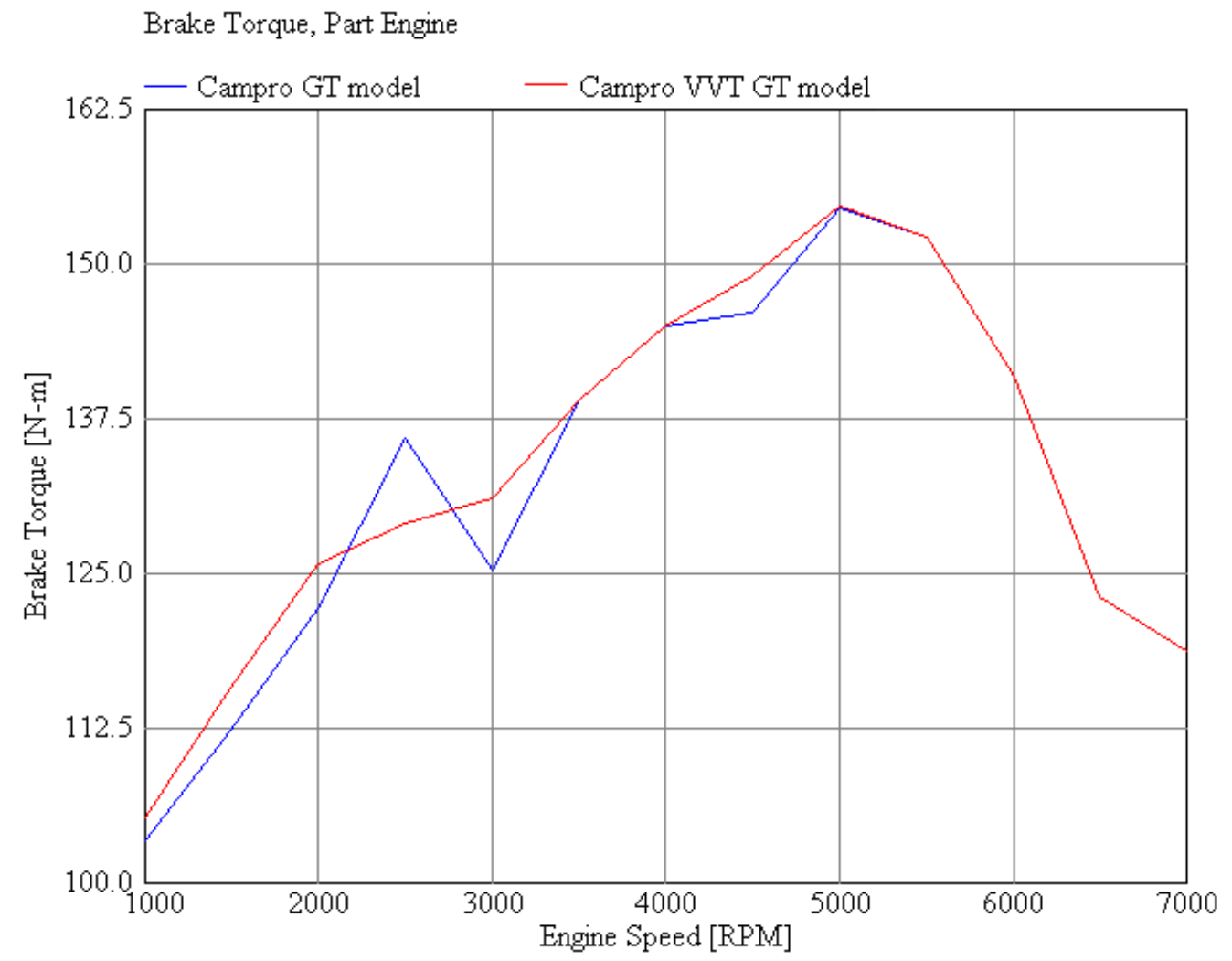

Fig. 15 Comparison of torque for CAMPRO GT model and CAMPRO GT model equipped with the Variable Valve Timing system 